\title{
Failure modes observed on worn surfaces of W-C-Co sputtered coatings
}

\author{
A. Ramalho ${ }^{a}$, A. Cavaleiro ${ }^{\text {a }}$ A. S. Miranda ${ }^{b}$ and M. T. Vieira ${ }^{a}$ \\ ${ }^{a}$ Departmento de Engenharia Mecânica, Universidade de Coimbra, P-3000 Coimbra (Portugal) \\ ${ }^{b}$ Departamento de Tecnologia dos Materiais e Metalomecânica, Universidade do Minho, P-4719 Braga Codex (Portugal)
}

\begin{abstract}
During scratch testing, the indenter gives rise to a distribution of stresses similar to that observed in tribocontacts. In this work, r.f.sputtered W-C-Co coatings deposited from sintered WC + Co $(6,10$ and $15 \mathrm{wt} . \% \mathrm{Co})$ at various substrate biases were scratched and tested tribologically and the morphology of the damaged surfaces was analysed. The cobalt content of the coatings is the main factor determining their tribological characteristics. The failure modes observed on the worn pin-on-disc tested surfaces are explained and compared with those obtained by scratch testing. In spite of it not being possible to establish quantitative results for the wear resistance of W-C-Co coatings from scratch testing, an estimation can be performed based on the observation of the failure modes in the scratch track. Thus scratch testing can be used to predict the tribological behaviour of coated surfaces. This possibility can reduce the number and cost of tribological tests.
\end{abstract}

\section{Introduction}

One of the most common methods of ircreasing the performance of wear-resistant components is to coat their surface with hard films. These coatings must withstand applied loads without losing their integrity.

Among the techniques which permit the evaluation of the adhesion of coatings to substrates, the scratch test has been the most widely used for the characterization of coated samples developed for tribological applications. In this test the adhesion is quantified by the normal load applied to the indenter which leads to detachment of the coating from the substrate. Nevertheless, different types of failure are frequently observed on the tracks of the scratches, giving rise to dinficulty in the unambiguous identification of the adhesive failure which determines the critical load $[1,2]$.

During tribological tests, one of the mechanisms usually referred to in the coating failure is the abrasion produced by particles cohesively or adhesively detached from the coating and embedded in the uncoated surface [3-5]. In spite of the conditions of contact being different in the two tests (normal load, radius of indenter tip vs. load per particle, radius of particles), the contact stresses arising from the indenter in a scratch test and from the embedded particles in a tribological test should be very similar. Thus similar failure modes for coatings in scratch and sliding tribological tests will be expected, although the correlations between the normal load and the load per particle required to produce detachment will be very difficult to determine $[6-10]$.
The main objective of this research was to try to identify by means of a simple test (scratch test) those samples which are worthwhile to be studied tribologically. Thus in this study, first the influence of the deposition ${ }^{*}$ conditions, particularly the substrate bias and the chemical composition of the target, on the types of failure mode observed in scratch and sliding tribological (pin-on-disc) tests will be presented. Secondly these failure modes will be compared and correlated with the friction and wear coefficients of the coated samples.

\section{Experimental details}

\subsection{Coating production}

The coatings were deposited by r.f. magnetron sputtering in an Edwards ESM 100 unit with two r.f. power supplies of 1000 and $500 \mathrm{~W}$ linked to the target and

TABLE 1. Experimental conditions of pin-on-disc tests

\begin{tabular}{ll} 
Disc & Coated AISI M2 HSS \\
Pin & Uncoated AISI 1045 steel \\
Radius of pin hemispherical end & $3 \mathrm{~mm}$ \\
Roughness of pin hemispherical surface & $0.7-1 \mu \mathrm{m}\left(R_{\mathrm{a}}\right)$ \\
Sliding speed & $0.5 \mathrm{~m} \mathrm{~s}^{-1}$ \\
Normal load & $4 \mathrm{~N}$ \\
Running time & 100000 turns \\
Environment & Air, room temperature \\
\hline
\end{tabular}


TABLE 2. Characteristics of W-C-Co films as a function of deposition conditions

\begin{tabular}{|c|c|c|c|c|c|c|c|c|c|}
\hline \multirow{3}{*}{$\begin{array}{l}\text { Substrate } \\
\text { bias } \\
\text { (V) }\end{array}$} & \multicolumn{3}{|c|}{ Structure } & \multicolumn{3}{|c|}{$\begin{array}{l}\text { Cobalt content }(\text { at. } \%) \\
(\% \mathrm{~W}+\% \mathrm{Co}=100 \%)\end{array}$} & \multicolumn{3}{|c|}{$\begin{array}{l}\text { Hardness } \\
\left(\mathrm{HV}_{d=10 \mu \mathrm{m}}\right)\end{array}$} \\
\hline & \multicolumn{3}{|c|}{ Target cobalt content (wt.\%) } & \multirow[b]{2}{*}{6} & \multirow[b]{2}{*}{10} & \multirow[b]{2}{*}{15} & \multirow[b]{2}{*}{6} & \multirow[b]{2}{*}{10} & \multirow[b]{2}{*}{15} \\
\hline & 6 & 10 & 15 & & & & & & \\
\hline 0 & A & A & A & 18 & 26 & 30 & 2242 & 1772 & 2131 \\
\hline-50 & $\begin{array}{l}\mathrm{W}_{2} \mathrm{C}+ \\
\mathrm{WC}_{1-x}\end{array}$ & A & A & 12 & 20 & 29 & 3479 & 2222 & 2258 \\
\hline-100 & $\begin{array}{l}\mathrm{W}_{2} \mathrm{C}+ \\
\mathrm{WC}_{1-x}\end{array}$ & A & A & 7 & 16 & 26 & 4106 & 2297 & $206=$ \\
\hline-200 & $\begin{array}{l}\mathrm{W}_{2} \mathrm{C}+ \\
\mathrm{WC}_{1-x}\end{array}$ & $\begin{array}{l}\mathrm{W}_{2} \mathrm{C}+ \\
\mathrm{WC}_{1-x}\end{array}$ & A & 3 & 6 & 21 & 3950 & 3242 & 245 \\
\hline-400 & $\begin{array}{l}\mathrm{W}_{2} \mathrm{C}+ \\
\mathrm{WC}_{1-x}\end{array}$ & $\begin{array}{l}\mathrm{W}_{2} \mathrm{C}+ \\
\mathrm{WC}_{1-x}\end{array}$ & A & 2 & 6 & 18 & 3710 & 3120 . & \\
\hline
\end{tabular}

A, amorphous; ${ }^{a}$ hardness determined using Thomas model [13].

substrate holder respectively. The targets were sintered tungsten carbide (WC) containing different percentages of cobalt $(6,10$ and 15 wt. $\%$ Co). M2 (AISI) high speed steel (HSS) heat treated (quenching and tempering) to $850 \mathrm{HV} 30$ was used as substrate.

The films were obtained in an argon atmosphere at a deposition pressure of $1 \mathrm{~Pa}$ and a target power density of $6.25 \mathrm{~W} \mathrm{~cm}^{-2}$; the negative substrate bias was varied in the range $0-400 \mathrm{~V}$. The deposition time was that

TABLE 3. Tribological and scratch test results for W-C-CO films

\begin{tabular}{lllll}
\hline $\begin{array}{l}\text { Substrate } \\
\text { bias (V) }\end{array}$ & Scratch & Disc & $\mu$ & $\begin{array}{l}\eta \\
\left(10^{-7} \mathrm{~m}^{2}\right)\end{array}$ \\
\hline
\end{tabular}

Films deposited from $W C+15 \%$ Co target

$\begin{array}{rllll}0 & \text { NC } & \text { NC } & \text { L } & \text { L } \\ -50 & \text { NC } & \text { NC } & \text { M } & \text { L } \\ -100 & \text { T } & \text { NC } & \text { M } & \text { L } \\ -200 & \mathrm{~B}+\mathrm{T} & \mathrm{B}+\mathrm{T} & \mathrm{H} & \mathrm{M} \\ -400 & \mathrm{~B}+\mathrm{T} & \mathrm{B}+\mathrm{T} & \mathrm{H} & \mathrm{H}\end{array}$

Films deposited from $\mathrm{WC}+10 \%$ Co target

$\begin{array}{rllll}0 & \text { NC } & \text { NC } & \text { L } & \text { L } \\ -50 & \text { T } & \text { NC } & \text { H } & \text { M } \\ -100 & \text { T } & \text { T } & \text { M } & \text { M } \\ -200 & \text { B } & \text { B } & \text { M } & \text { H } \\ -400 & \text { B } & \text { B } & \text { H } & \text { H }\end{array}$

Films deposited from $W C+6 \%$ Co target

\begin{tabular}{rllll}
0 & $\mathrm{~T}$ & $\mathrm{NC}$ & $\mathrm{L}$ & $\mathrm{L}$ \\
-50 & $\mathrm{~T}$ & $\mathrm{~T}$ & $\mathrm{H}$ & $\mathrm{M}$ \\
-100 & $\mathrm{~B}$ & $\mathrm{~B}$ & $\mathrm{M}$ & $\mathrm{H}$ \\
-200 & $\mathrm{~B}$ & $\mathrm{~B}$ & $\mathrm{M}$ & $\mathrm{H}$ \\
-400 & $\mathrm{~B}$ & $\mathrm{~B}$ & $\mathrm{M}$ & $\mathrm{H}$ \\
\hline
\end{tabular}

Key: $\mu$, friction coefficient $(\mathrm{L} \leqslant 0.45,0.45 \leqslant \mathrm{M} \leqslant 0.7, \mathrm{H} \geqslant 0.7) ; \eta$, planimetric wear $(L \leqslant 4.5,4.5 \leqslant M \leqslant 6.5 ; H \geqslant 6.5) ; N C$, not cracked; $T$, tensile cracking; $\mathrm{B}$, buckling. necessary to obtain a film thickness of approximately $2 \mu \mathrm{m}$.

\subsection{Coating characterization}

Scratching was carried out in a CSEM-Revetest using a continuous normal applied load in the range $0-100 \mathrm{~N}$ and under the following standard conditions: diamond tip radius $R=0.2 \mathrm{~mm}$, scratching speed $\mathrm{d} x / \mathrm{d} t=$ $10 \mathrm{~mm} \mathrm{~min}^{-1}$, loading rate $\mathrm{d} l / \mathrm{d} t=100 \mathrm{~N} \mathrm{~min}^{-1}$. Four scratches were applied to each sample. In order to evaluate the effect of cyclic load applications during tribological testing, tests were carried oui at constant load with multiple passage in the same scratch.

A pin-on-disc tribometer was used to characterize the tribological behaviour of coated M2 (AISI) high speed steel discs against uncoated 1045 (AISI) carbon steel pins with the contact conditions summarized in Table 1 .

The tests were performed continuously and the wear measured at the end of each test. The pin wear was determined from measurement of the pin circular wear scar by optical microscopy. The disc wear was evaluated by measuring the area on recorded profiles obtained perpendicular to the sliding direction.

A load cell incorporated into the pin-on-disc tester enables the continuous determination of the friction force during each test. The selected parameter to compare the wear resistance was the total planimetric wear, i.e. the sum of the transversal area measured on the pin and on the disc.

The morphologies of surfaces after the scratch tests and of the wear surfaces were observed by optical and scanning electron microscopy (SEM) and the type of coating failure was determined.

The use of energy-dispersive X-ray spectroscopy (EDXS) permitted the identification of detachment of the coatings and the possible occurrence of debris transfer between the elements of the sliding pair. 


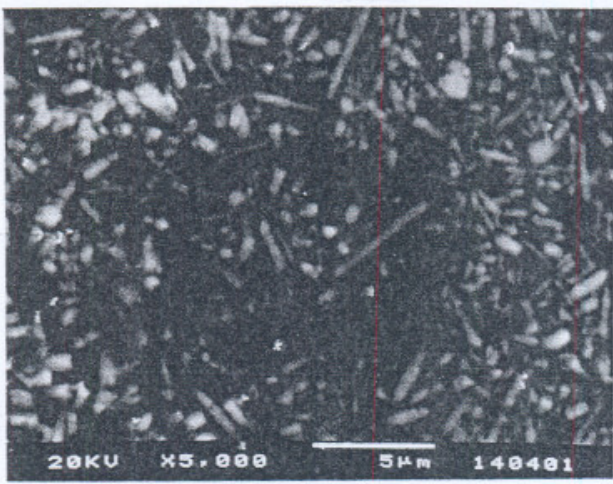

(a)

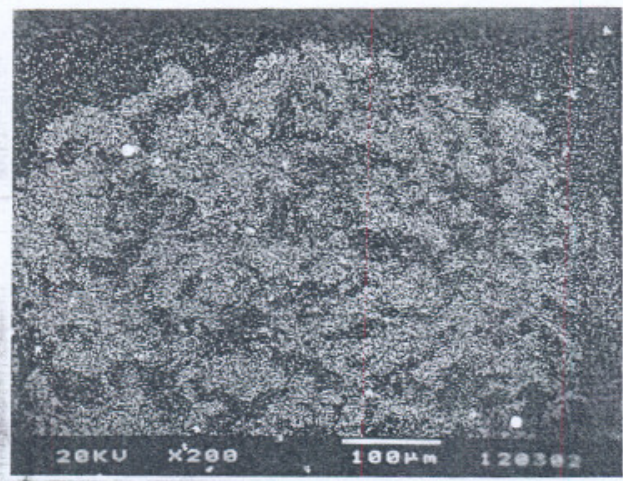

(c)

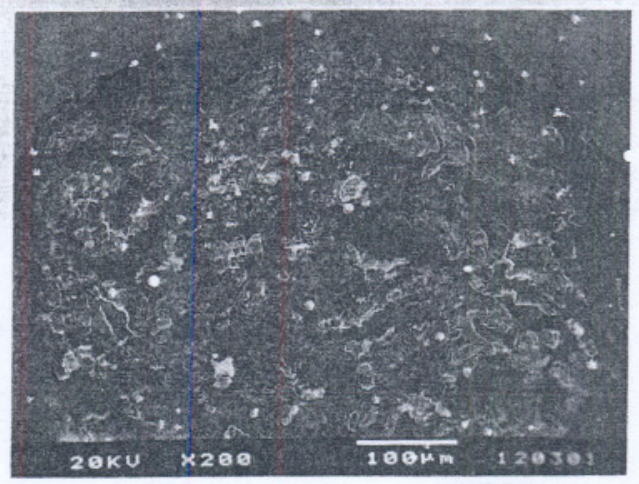

(b)

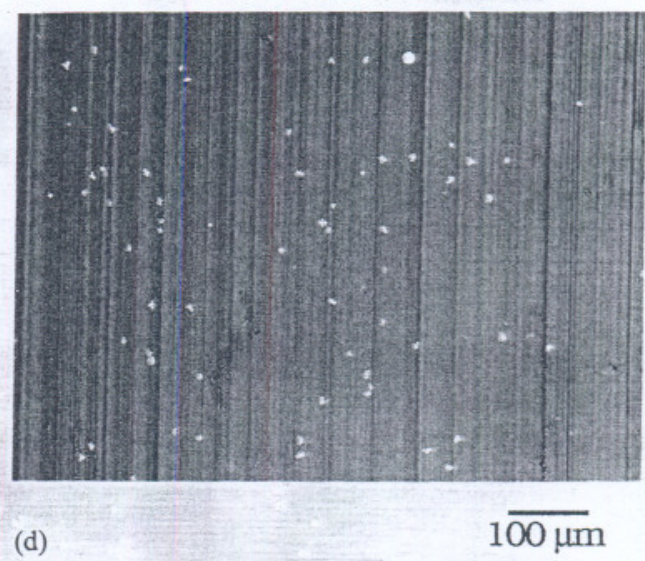

Fig. 1. Micrographs relating to the tribological testing of a W-C-Co coating with high cobalt content ( 26 at. $\%$ Co): (a) wear debris morphology (SEM); (b) pin surface covered by transferred W-C-Co film particles (SEM); (c) X-ray map of tungsten on pin surface (SEM); (d) worn surface of coated disc (optical).

\section{Results and discussion}

Table 2 summarizes the main results on the structure, chemical composition and hardness of the $\mathrm{W}-\mathrm{C}-\mathrm{Co}$ sputtered coatings $[11,12]$. From an analysis of this table it is possible to conclude that the cobalt content is the most important parameter contributing to the properties of the films and that its percentage in the film depends on its content in the target and on the substrate bias used in the deposition. There are clearly two groups of films, one with high cobalt content (greater than 16 at. \%) and the other with lower cobalt content, which present different characteristics. The films belonging to t'ie first group have an amorphous structure and a lower hardness than the crystalline coatings of the second group.

In a previous study [12] it was verified that the cobalt content in W-C-Co films determined their failure mode when they were submitted to scratch testing. Taking into account the different failure modes indicated by Burnett and Rickerby [1], in this work for high cobalt films cohesive failures (tensile cracking) were observed, whereas low cobalt content films showed mainly adhesive failures of the buckling or chipping type.

Table 3 summarizes all the results on the tracks observed in the tribological and scratch test and the values of the friction and wear coefficients of the films. An analysis of this table allows us to conclude that the main factor determining the wear rate of the $\mathrm{W}-\mathrm{C}-\mathrm{Co}$ coatings is cracking of the film, particularly when it is of the buckling type. In this case the particles detached from the coating and embedded in the pin surface give rise to further cracking and detachment of the coating and consequently to its severe damage.

The pin-on-disc results and the morphological analysis of the worn surfaces and wear debris collected after the test reveal different wear mechanisms. After the first rotations the repeated contact of the pin against the disc gives rise to particle detachment from the coated surface; these particles are formed by a fracture process which occurs prefereatially on the coating surface close to the areas of high defect density. The behaviour of these particles at the interface of the pair contact depends on their hardness and cobalt content, which in turn deter- 


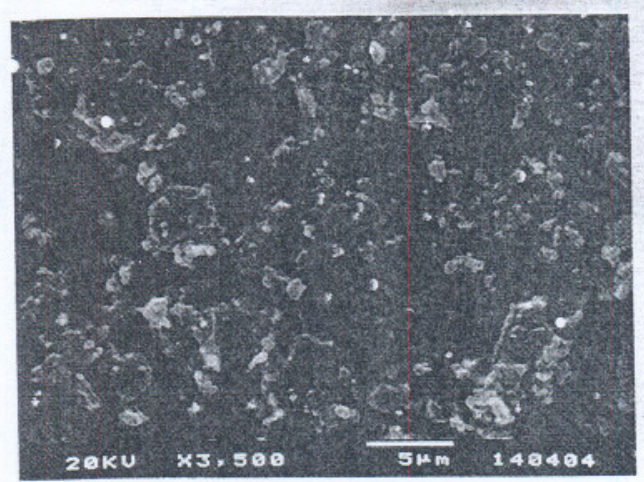

(a)

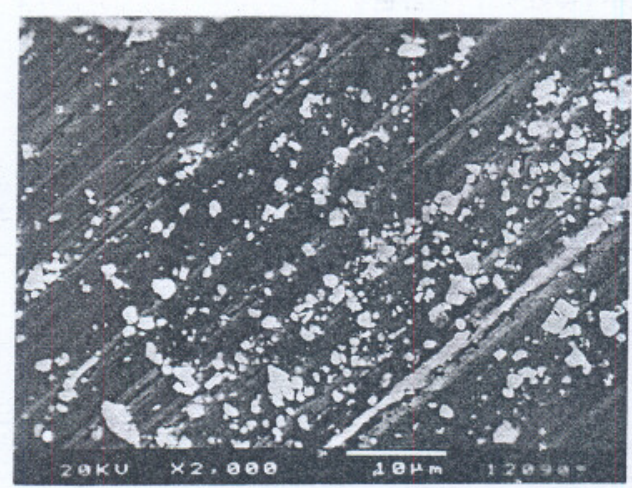

(b)

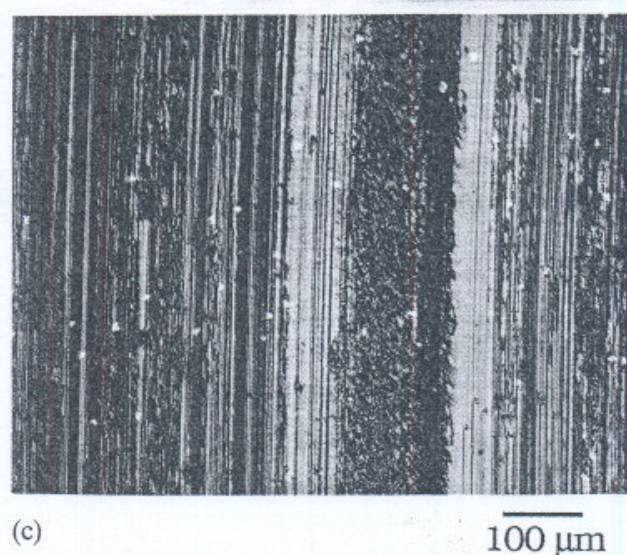

Fig. 2. Micrographs relating to the tribological testing of a W-C-Co coating with low cobalt content ( 6 at.\% Co): (a) wear debris morphology (SEM); (b) pin surface showing embedded W-C-Co particles (SEM); (c) worn surface of coated disc (optical).

mine their propensity to conformation and agglomeration under the rolling action of the pin. Two different behaviour types were observed as a function of the cobalt content in the coatings, although at this moment it is not possible to conclude whether the influence of the cobalt is due only to this or whether it arises indirectly owing to the modifications of the structure and hardness of the coatings.
For the films with high cobalt content the wear debris is present mainly in form of rods (Fig. 1(a)), revealing that the wear mechanism occurs by microcutting. These particles adhere to the pin surface, forming a protective layer after suffering conformation and agglomeration (Figs. 1(b) and (c)). This mechanism gives rise to a low wear rate in both the pin and the disc (Fig. 1(d)) and low friction coefficients.

For harder films with lower cobalt content the wear debris consists of larger particles with polyhedral forms (Fig. 2(a)). Owing to their greater hardness, the compression produced by the pin contact gives rise to their partial embedding in the pin surfaces instead of their deformation (Fig. 2(b)). The abrasive action and multiple contact of the prominent particles with the disc tracks produce microcracking of the coating and the continuous formation of wear debris. This severe abrasion process gives rise to high wear rates and friction coefficients (Fig. 2(c)).

Comparison between the failure modes observed on the wear and scratch tracks of the films shows that they are very similar. Figure 3(a) shows details of the wear surface of a high cobalt content $\mathrm{W}-\mathrm{C}-\mathrm{Co}$ film after 100000 turns. There is no sign of cracking as observed in the scratch test on the same film (Fig. 3(b)). For lower percentages of cobalt the cracking observed in both tracks (wear and scratch) can be cohesive (tensile cracking, Figs. 4(a) and 4(b)) or adhesive (buckling and chipping), although a superposition of these two failures could also be observed (Figs. 5(a) and 5(b)). In this figure particles detached by a chipping process are clearly seen, which is made easy by the interference of contiguous tracks.

The similarity of failure modes was observed in almost all cases studied. However, the scratch test seems to be more destructive than the pin-on-disc test.

To simulate the process of wear debris formation by cyclic contacts of the embedded particles with the coated surfaces, scratch tests were performed at constant load with multiple passages on the same scratch. Figure 6 shows the surface degradations observed after several consecutive passages of the indenter over the coated surface. Evaluation of the lateral deformation of the track by determining the profile with a surface-measuring instrument (Fig. 6) allows us to conclude that the plastic deformation of the substrate increases with increasing number of passages, in such a way that after a certain level of deformation film cracking and chipping can occur with the consequent detachment of coating particles. Nevertheless, the multipass scratch test applied to high cobalt content films does not give rise to any type of cracking in the track of the scratch after a high number of passages (20) even for loacis as high as $40 \mathrm{~N}$ (Fig. 7), although the high lateral plastic deformation gives rise to small lateral cracks (Fig. 7(c)). These results 


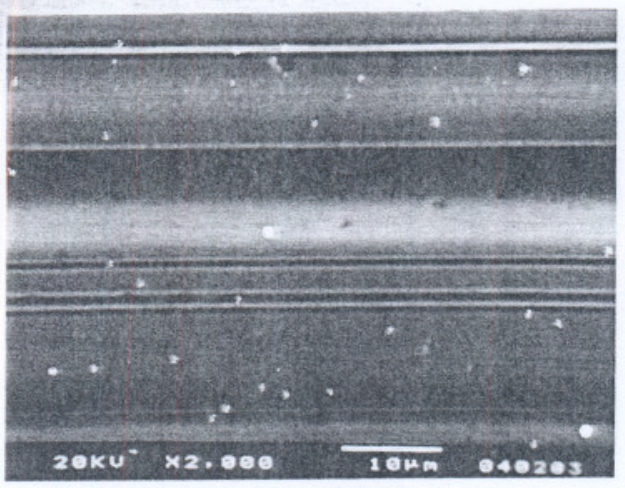

(a)

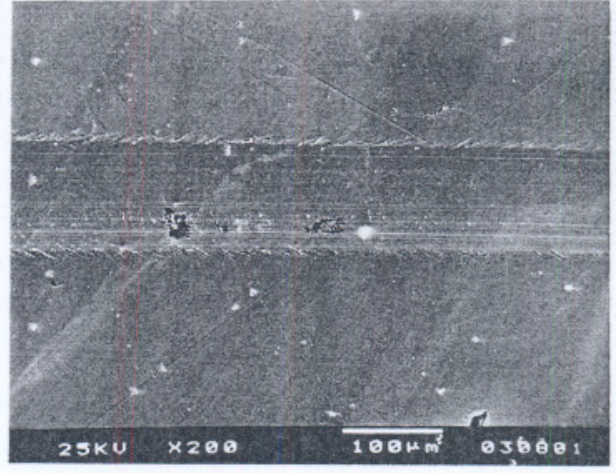

(b)

scratch direction

Fig. 3. SEM images showing the failure mode of a W-C-Co coating with high cobalt content ( 30 at.\% Co) (a) in a pin-on-disc tribological test and (b) in a scratch test.

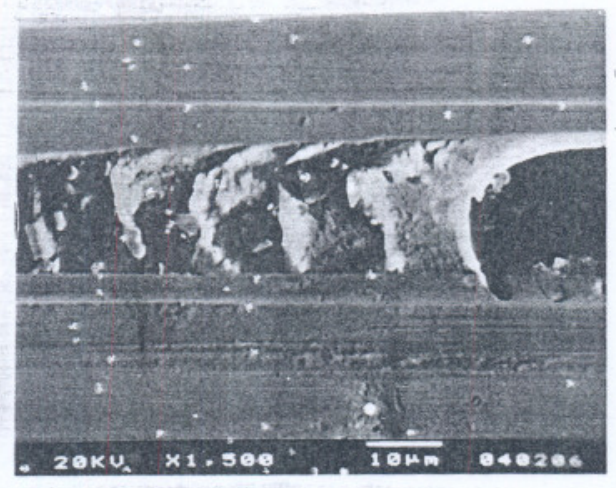

(a) sliding direction

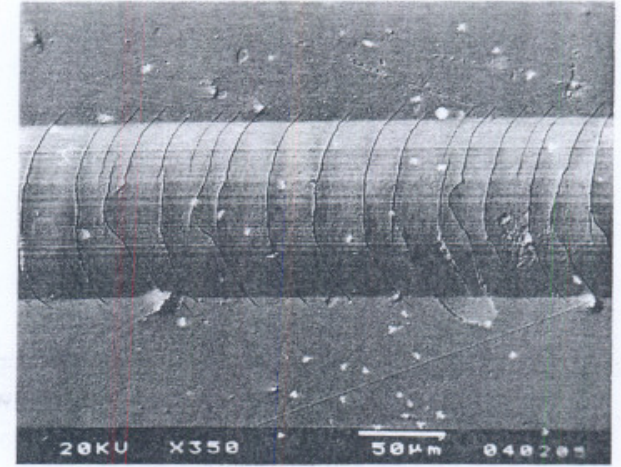

(b)

Fig. 4. SEM images showing the failure mode of a W-C-Co coating with medium cobalt content $(20$ at. $\%$ Co) (a) in a pin-on-disc tribological test and (b) in a scratch test.

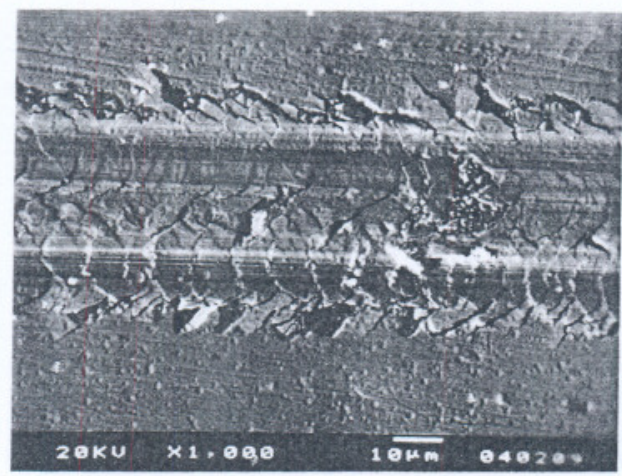

(a) sliding direction

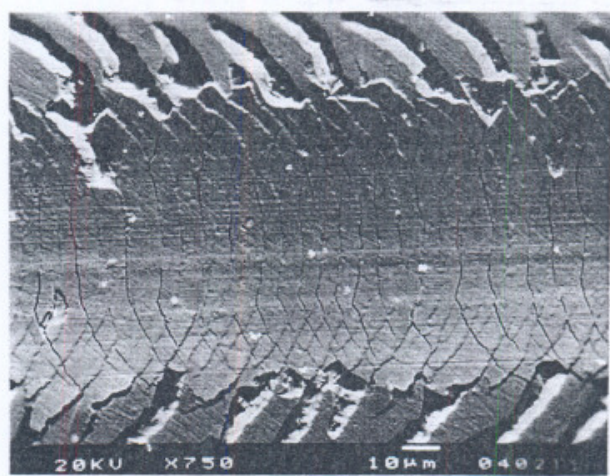

(b)

\section{scratch direction}

Fig. 5. SEM images showing the failure mode of a W-C-Co coating with low cobalt content ( 6 at. $\%$ Co) (a) in a pin-on-disc tribological test and $(b)$ in a scratch test.

demonstrate that it is always possible to observe the characteristic failure mode of a coating, whatever the load applied to the indenter, if a sufficient number of passages are performed in the same track. Thus, as was shown above, similar failure modes for scratch and sliding tribological tests should be expected, although different forms of the indenter tip and applied loads are used in the tests. 
(a)

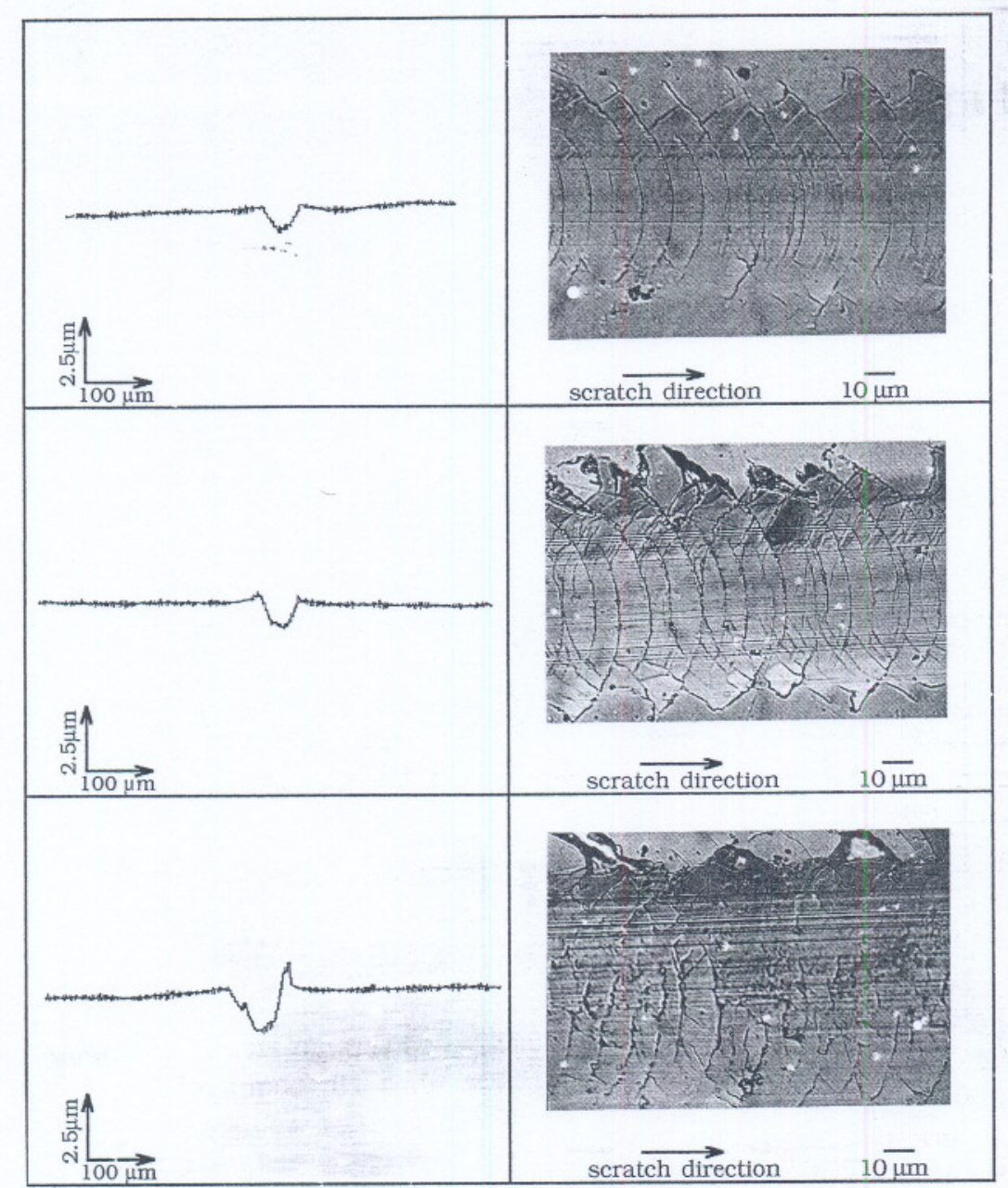

Fig. 6. Optical micrographs and transversal profiles of the scratch track of a W-C-Co coating with low cobalt content ( 3 at.\% Co) carried out under a constant load of $20 \mathrm{~N}$ after (a) one passage, (b) three passages and (c) five passages.

The correlation between the scratch and tribological test results does not allow us to predict quantitatively the wear resistance of a W-C-Co-coated material by the realization of only a scratch test. Nevertheless, by analysing the failure mode observed in the track of the scratch, an estimation of the sliding damage of the coating can be obtained even if the tribological test is different from the pin-on-disc test used in this work.

\section{Concluding remarks}

The cobalt content of $\mathrm{W}-\mathrm{C}-\mathrm{Co}$ sputtered films determines their structure and hardness as well as their response to scratch and tribological tests. Films with low cobalt content present the highest friction and wear coefficients, which is attributed to the embedding of detached coating particles in the pin surface. These particles give rise to cracking of the coating and further detachment of wear debris.
The failure modes cbserved on the worn coated surface were shown to be very similar to those obtained by scratch testing. By using multipass scratch testing under various loads, it was possible to simulate the detachment of coating particles and to show the independence of the load vaiue on the typical failure mode obtained for a coating.

As a final conclusion, analysis of the failure modes observed in the scratch tracks of $\mathrm{W}-\mathrm{C}-\mathrm{Co}$ films allows us to estimate the tribological behaviour of these coatings, although no quantitative results can be predicted.

\section{References}

1 P. J. Burnett and D. S. Rickerby, Thin Solid Films, 154 (1987) 403.

2 J. Oroshnik and W. K. Croll, in K. L. Mittal (ed.), Adhesion measurement of thin-films, thick-films and bulk coatings, ASTM Spec. Tech. Publ. 640, ASTM, Philadelphia, PA, 1978, p. 158.

3 K. A. Taylor, Thin Solid Films, 40 (1977) 189. 
(a)

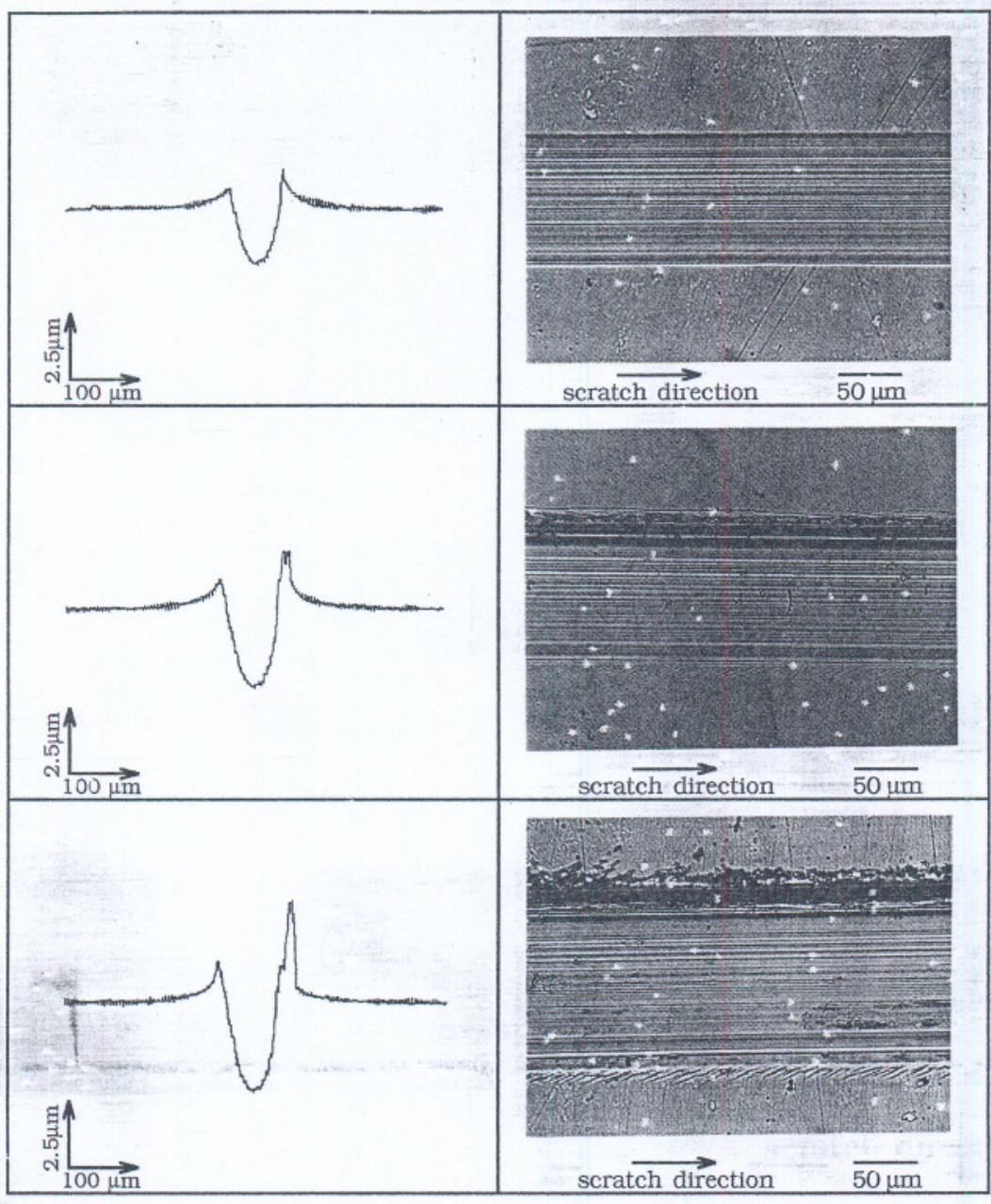

(c)

Fig. 7. Optical micrographs and transversal profiles of the scratch track of a W-C-Co coating with high cobalt content (30.at.\% Co) carried out under a constant load of $40 \mathrm{~N}$ after (a) one passage, (b) five passages and (c) 20 passages.

4 E. Eser, R. E. Ogilvie and K. A. Taylor, J. Vac. Sci. Technol., 15 (1987) 401.

5 B. Malliet, J. P. Celis, L. M. Stals and M. V. Stapper, Wear, 142 (1991) 151.

6 D. J. Rich, A. J. Perry and P. F. Woerner, Thin Solid Films, 154 (1987) 417.

7 D. T. Gawne and U. Ma, in K. C. Ludema (ed.), Proc. Conf. on Wear of Materials 1987, ASME, New York, 1987, p. 517.
8 D. T. Gawne, and U. Ma, Wear, 129 (1989) 123.

9 S. J. Bull and D. S. Rickerby, Thin Solid Films, 181 (1989) 545.

10 R. Rochotzki, J. Vetter and E. Weißmantel, Thin Solid Films, 198 (1991) 103.

11 A. Cavaleiro, G. Lemperière and M. T. Vieira, Thin Solid Films, 197 (1991) 232.

12 A. Cavaleiro and M. T. Vieira, Mater. Sci. Eng. A, 140 (1991) 631.

13 A. Thomas, Surf. Eng., 3 (1987) 117. 